\title{
Laser Capture Microdissection-Guided Fluorescence In Situ Hybridization and Flow Cytometric Cell Cycle Analysis of Purified Nuclei from Paraffin Sections
}

Lisa M. DiFrancesco, M.D., Sabita K. Murthy, Ph.D., Joanne Luider, BSc, Douglas J. Demetrick, M.D., Ph.D.

Departments of Pathology, Oncology, and Medical Biochemistry (LMD, SKM, DJD), The University of

Calgary, and Calgary Laboratory Services (LMD, JL, DJD), Calgary, Alberta, Canada

Laser capture microdissection (LCM) has recently been identified as a quick, simple, and effective method by which microdissection of complex tissue specimens for molecular analysis can be routinely performed. Assessment of gene copy number by fluorescence in situ hybridization (FISH) is useful for the analysis of molecular genetic alterations in cancer. Unfortunately, the application of FISH to paraffin sections of tumor specimens is fraught with technical difficulty and potential artifacts. Our results demonstrate that LCM-microdissected nuclei are suitable for FISH gene copy analysis. Amplification of genes in cancer specimens can be detected as easily in LCM-prepared nuclei as in fresh nuclei from cancer tissue specimens. Furthermore, contamination of tumor specimens by normal cells can make interpretation of flow cytometric cell cycle analysis difficult. Our results show that LCMmicrodissected nuclei can also be used for flow cytometric cell cycle and ploidy analysis.

LCM/FISH offers the advantages of multicolor FISH in a morphologically defined cell population, without the technical problems of FISH performed on paraffin sections. This technique should further simplify the methodology required to perform copy number analysis of tumor suppressor or protooncogenes in archived cancer specimens. The use of LCM specimens will also improve the specificity and simplify the interpretation of flow cytometric cell cycle and ploidy analysis of breast cancer specimens.

Copyright () 2000 by The United States and Canadian Academy of Pathology, Inc.

VOL. 13, NO. 6, P. 705, 2000 Printed in the U.S.A

Date of acceptance: December 28, 1999.

This work was funded by the Canadian Breast Cancer Research Initiative and the Alberta Cancer Board.

Address reprint requests to: Dr. D. Demetrick, The University of Calgary, 3330 Hospital Drive, NW, Calgary, Alberta, Canada T2N 1N4; e-mail: demetric@ucalgary.ca; fax: 403-283-8727.
KEY WORDS: Cancer genetics, Flow cytometry, Fluorescence in situ hybridization, Laser capture microdissection, Ploidy.

Mod Pathol 2000;13(6):705-711

The identification of consistent genomic alterations in cancer specimens may provide important diagnostic or predictive information. Although immunohistology is often used to measure gross up- or downregulation of genes, identification of structural genomic alterations such as gene amplification, deletion, or translocation may also contribute useful information. For example, with standardization of reagents and methods, it now seems clear that amplification and/or overexpression of c-erbB-2 correlates with adverse outcome in breast carcinoma (1-3). It is surprising that gene amplification can be a better predictor of outcome than overexpression $(1,4)$. Discordance between copy number and gene expression has also been described in several oncogenes or tumor suppressor genes in addition to c-erb-B-2 (5-7), such as c- $m y c$ (8), $R B 1(9,10)$, and $p 53$ (11-13). Such discordance may necessitate gene copy number analysis rather than immunohistologic methods.

One of the best methods of identifying major genetic structural alterations in nuclei is to use fluorescence in situ hybridization (FISH). This method usually works best with fresh or frozen tissue and offers localization of a genomic abnormality to a specific cell-very valuable in cancer specimens that are commonly contaminated with normal tissue elements such as inflammatory cells or fibroblasts. Copy numbers of genes such as c-erb-B-2 (4, 14-18), c-myc (19), RB1 (20), the insulin receptor gene (21), CCND1 (22), and others have been evaluated in clinical specimens by FISH. Heterogeneity of gene copy number may be a useful additional feature to assess in cancer specimens, as evidence suggests that metastasis likely occurs via specific dominant clones in the primary tumor (23, 24). Assessment of tumor heterogeneity, thus, may 
add more useful information to the assessment of a specimen than copy number analysis alone.

Unfortunately, many pathologic specimens are fixed in formalin and embedded in paraffin before diagnosis. FISH of paraffin sections has proved to be very difficult and prone to artifact from autofluorescence, incomplete (sectioned) nuclei, high background, excessive probe requirement, and poor probe penetration $(25,26)$. Protocols to isolate the nuclei from paraffin-embedded tissues have been described in the literature $(27,28)$. Without pretreatment, however, investigators report that formalin-fixed, paraffin-embedded extracted nuclei show poor efficiency of hybridization in FISH assays (29). Furthermore, isolation of nuclei from whole sections necessitates that the specimen be an almost pure collection of tumor cells before any meaningful analysis can occur. This can be difficult to achieve, as many cancer specimens are "contaminated" by stromal proliferation or inflammation. Simple methods to identify gene copy number from formalin-fixed, paraffin-embedded cancer specimens would therefore find wide application in the study of molecular correlates of tumor progression.

Cell cycle analysis of tumor specimens has been shown to be of some value in estimating risk of progression in breast cancer. High S-phase fraction, for example, has been shown to add prognostic information in subsets of breast cancer cases (30, 31). The estimation of this indicator can be complicated by several factors, including tumor cell purity. Although algorithms have been designed to minimize some of these problems (30), ensuring that a flow cytometry sample is composed exclusively of tumor cells is the best way to avoid artifacts that result from normal cell contamination. Staining the specimens with cytokeratin and using dual-label gating has been useful in at least confining the analysis to epithelial cells, resulting in better quality results (32); however, normal epithelial cells are still able to contaminate the analysis. A better method of ensuring that only the neoplastic cells are analyzed is needed.

The development of the laser capture microdissection (LCM) technique allows for the highresolution dissection of cells from frozen and formalin-fixed, paraffin-embedded tissue sections. This technology depends on the laser activation of a polymeric film that then becomes focally adhesive. When this film overlies a dehydrated tissue specimen, the zone of adhesion allows precise dissection of cell groups within a tissue section. Specimen dissection diameters as small as $7 \mu$ are possible. This technique essentially negates the issue of contamination by non-neoplastic cells (33). LCM has been used to dissect cells for specific mRNA isolation (34), DNA isolation for genetic analysis (35) or comparative genomic hybridization (36), and protein analysis (37). This method seems to have great potential, therefore, for the isolation of tumor nuclei that could then be subjected to multicolor FISH analysis or flow cytometry. Confining the analysis to specific cells may also decrease the autofluorescence in sections caused by extracellular matrix or collagen. The temperature shock of approximately $70^{\circ} \mathrm{C}$ (Dr. B. Bonner, National Institutes of Health, personal communication, October 1997) and the adherence to the plastic film associated with LCM are possible barriers to the recovery of nuclei for subsequent FISH analysis. We evaluate the potential of LCM of breast carcinoma cells from paraffin sections to yield nuclei that are suitable targets for FISH quantitation of gene copy number and for flow cytometric analysis of cell cycle parameters.

\section{MATERIALS AND METHODS}

Specimens of normal breast and breast carcinoma were fixed in $10 \%$ neutral buffered formalin and embedded in Surgiplast matrix. Concurrently, frozen specimens of breast carcinoma were used to produce touch preparations for FISH analysis. The touch preparations were prepared using previously described methods (22). Six- to $20-\mu$ sections were cut from the paraffin blocks, stained with Harris's hematoxylin, dehydrated through a graded ethanol series to xylene, and then allowed to air dry. Staining with eosin yielded wide-spectrum background fluorescence that interfered with subsequent fluorescent analysis and was therefore eliminated. Dehydrated sections were subjected to LCM using a Pix Cell LCM instrument (Arcturus Engineering, Inc., Mountain View, CA) following manufacturer's protocols. Cells and cell nests were fixed to the polymer film on CapShur LCM caps (Arcturus Engineering) and placed tightly into 0.5 - $\mathrm{mL}$ microfuge tubes. They were stored for up to 1 year at room temperature with no ill effect before nucleus extraction. Nuclei were extracted by optimization of published methods (38). Briefly, $100 \mathrm{uL}$ fresh, highquality chloroform was pipetted into a $0.5-\mathrm{mL}$ microfuge tube and capped with a CapShur LCM cap containing a microdissected specimen. The tube was inverted for 10 seconds, then microcentrifuged at $3000 \mathrm{~g}$ for 30 seconds to release the tissue specimen from the "capture" polymer of the LCM cap. The LCM cap was then removed, and 200 $\mathrm{uL}$ anhydrous ethyl ether was added and mixed with the chloroform by inversion. This step is necessary to lower the density of the solvent to allow successful centrifugation of the tissue fragments while ensuring that the polymer capture medium was still soluble. After microfuge centrifugation, the supernatant was removed by vacuum suction with 
a narrow pipette tube and the pellet was washed two times as above with $300 \mathrm{uL}$ fresh xylene to remove dissolved LCM cap polymers, taking care not to disturb the fragile tissue pellet. The sample was then washed once with $400 \mathrm{uL}$ absolute ethanol to remove xylene, followed by one wash with $95 \%$ ethanol, one wash with $70 \%$ ethanol, and two washes with TE (10 mm Tris, 1 mM EDTA, pH 8.0) for rehydration. The sample was finally washed once with $400 \mathrm{uL}$ proteinase buffer $(50 \mathrm{~mm}$ Tris, $10 \mathrm{~mm}$ $\mathrm{NaCl}, 10$ mm EDTA, $\mathrm{pH}$ 8.0) and resuspended to a final volume of $100 \mathrm{uL}$. Proteinase K was added (50 $\mathrm{uL}$ at $0.015 \%$ to a final concentration of $0.005 \%$ ). The digest was incubated for 30 to $60 \mathrm{~min}$ at $37^{\circ} \mathrm{C}$, with gentle finger vortexing approximately every 10 min. For FISH analysis, the sample was diluted with $350 \mathrm{uL} \mathrm{TE}$, and the liquid was gently removed to leave undigested tissue fragments in the tube, then centrifuged for $5 \mathrm{~min}$ at 10,000 $\mathrm{g}$ followed by careful removal of as much supernatant as possible without disturbing the pellet. The pellet was then gently resuspended in approximately $50 \mathrm{uL} 10 \mathrm{~mm}$ Tris $\mathrm{pH}$ 8.0 by pipetting with a wide-bore pipette tip, and the suspension was pipetted onto clean microscope slides ( 1 to $20 \mathrm{uL}$, depending on the concentration of nuclei). Circling the site of sample application with a diamond pencil on the underside of the slide was helpful to later visualization. The slides were allowed to air dry, then fixed in methanol:glacial acetic acid (3:1), air dried, and baked at $37^{\circ} \mathrm{C}$ for $4 \mathrm{~h}$ before hybridization. Slides were stored at $-20^{\circ} \mathrm{C}$ in slide boxes sealed within hybridization bags containing Drierite desiccant.

For flow cytometric analysis, the specimen was diluted with $350 \mathrm{uL}$ TE, then the liquid phase was gently removed to another tube to leave any undigested tissue fragments in the original tube. As an option, the liquid was then centrifuged at $3000 \mathrm{~g}$ for $1 \mathrm{~min}$ and resuspended in buffer for propidium iodide staining and flow cytometric analysis, but this step sometimes lowered the yield. Although a lot of steps are needed, batch handling can easily result in the purification of more than 20 specimens in an afternoon.

FISH was performed on the LCM and touch preparations according to our usual methodology (22). A variety of labeled genomic probes including cosmids for human cyclin D1 (CCND1; cloned from a placental genomic cosmid library) and $R B 1$ (obtained from RZPD, Heidelberg, Germany) were used for hybridization (Figs. 1 and 2). Fluorescent images were captured with a PXL1400 cooled CCD camera (Photometrics, Phoenix, AZ) using Electronic Photography software (BioDx, Pittsburgh, PA). Bright-field images were captured with a Spot 1 digital camera (Diagnostic Instruments, Inc., Sterling Heights, MI).

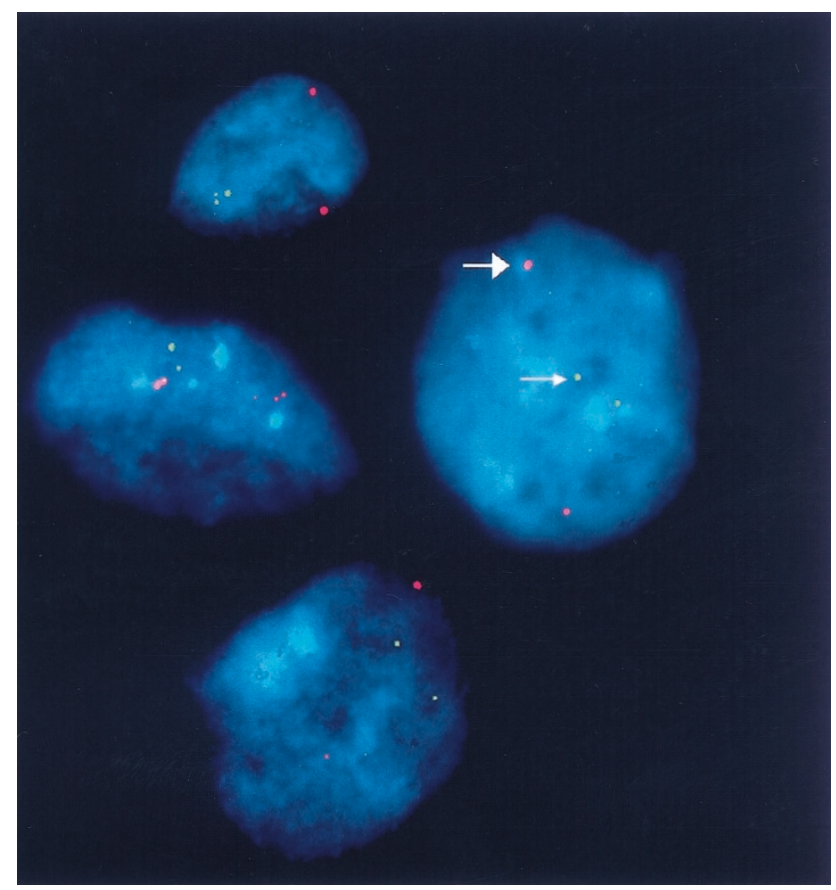

FIGURE 1. Laser capture microdissection/fluorescence in situ hybridization of normal breast epithelial cells. Twenty-micron paraffin sections of formalin-fixed normal breast tissue were subjected to laser capture of normal epithelial cells. The nuclei were prepared and subjected to fluorescence in situ hybridization using CCND1 (red, large arrows) and RB1 (green, small arrows) cosmid genomic probes. Nuclei show the expected normal copy number for each gene of two to four, depending on the stage of cell cycle of the cells.

Purified nuclei for flow cytometric analysis were stained in phosphate buffered saline containing 50 $\mathrm{ug} / \mathrm{mL}$ propidium iodide as per standard protocols (39). Stained nuclei were analyzed on a BeckmanCoulter Model Epics XL flow cytometer (Fullerton, CA) using a 1024 channel single parameter histogram. Flow rate was less than 100 events per second to minimize coincidence, and double discrimination was used.

\section{RESULTS AND DISCUSSION}

Figure 1 shows FISH of nuclei isolated from microdissected normal breast epithelial cells with genomic probes for cyclin D1 (CCNDI) and $R B 1$. The expected two to four copies of each gene are easily identified. Because only the nuclei are present on the slide and cellular RNA is somewhat degraded during the prefixation or fixation process, the background is usually cleaner than touch preparations of viable cells. As gene amplification can be easily demonstrated by FISH in touch preparations of cancer specimens, it was appropriate to compare LCM nuclei with fresh nuclei from specimens known to have amplification of a proto-oncogene. Figure 2 shows a comparison of two independent cases of primary infiltrating duct carcinoma of breast. Both specimens have a histologic grade of 2 

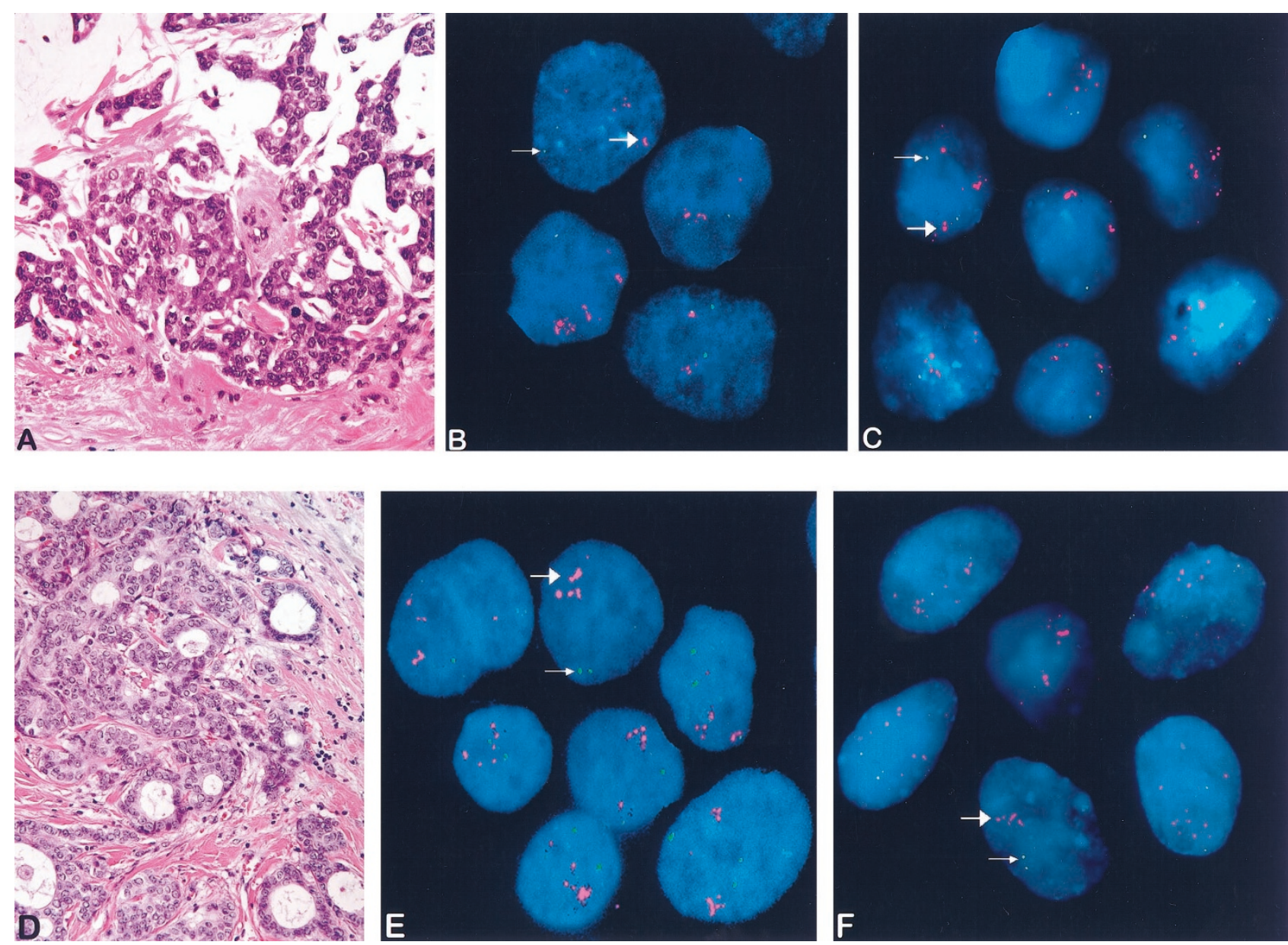

FIGURE 2. Laser capture microdissection/fluorescence in situ hybridization (FISH) of infiltrating duct carcinoma cells. Twenty-micron paraffin sections from two different cases of infiltrating duct carcinoma were subjected to laser capture of cells or cell groups from formalin-fixed breast cancer tissue (A-C, D-F). The nuclei were prepared and subjected to FISH using CCND1 (red, large arrows) and RB1 (green, small arrows) cosmid genomic probes and compared with FISH of touch preparations of the fresh tumors. A and D, typical histology of the two cases, respectively. B and E, FISH of the touch preparations. Amplification of CCND1, illustrated by an increase of gene copy number greater than six to eight, are shown in both cases. $\mathbf{C}$ and $\mathbf{F}$, FISH of the laser capture microdissection preparations. In all cases, $R B 1$ copy number is normal.

by modified Bloom-Richardson criteria (40). Amplification of CCND1 is seen clearly in nuclei of both the touch preparations and the LCM specimens, whereas the $R B 1$ signal is present at the usual two to four copies per cell. As for Figure 1, the background staining is less in the LCM specimen. Although our results show gene amplification or normal copy numbers, loss of specific genes may also be amenable to detection with this technique.

LCM-dissected specimens harvested from $20-\mu$ sections were stained with propidium iodide and subjected to flow cytometric analysis to identify cell cycle parameters and ploidy (Fig. 3). As can be seen, specimens from the two cases described in Figure 2 show normal ploidy but differing S-phase fractions. The coefficient of variation for the peaks is less than $5 \%$, showing high technical quality of the specimens. These results indicate that flow cytometric analysis of LCM specimens is feasible.

FISH of formalin-fixed, paraffin sections has proved to be very difficult and prone to artifact from autofluorescence, incomplete (sectioned) nu- clei, excessive background, excessive probe requirement, and poor probe penetration (26). Attempts have been made to improve the probe penetration and hybridization efficiency of such samples but have not been widely accepted (29). Some chemical methods of reducing autofluorescence have been shown to increase signal-to-noise ratios (41) but do not completely suppress this problem. Other approaches have utilized pixel subtraction algorithms to reduce autofluorescence (42). Methods of examining tissue sections using confocal microscopy have been developed (43) but are not feasible for most pathology applications, as the equipment is uncommon, the morphology can be difficult to appreciate, probe penetration of thick specimens is inefficient, and small probes have a short lifespan in the intense light required to penetrate thick sections. FISH using tyramide-based amplification on paraffin specimens has been reported $(26,44)$, and these kits are offered commercially. Though this seems to be a useful and simple technique, the problems of autofluorescence, inef- 

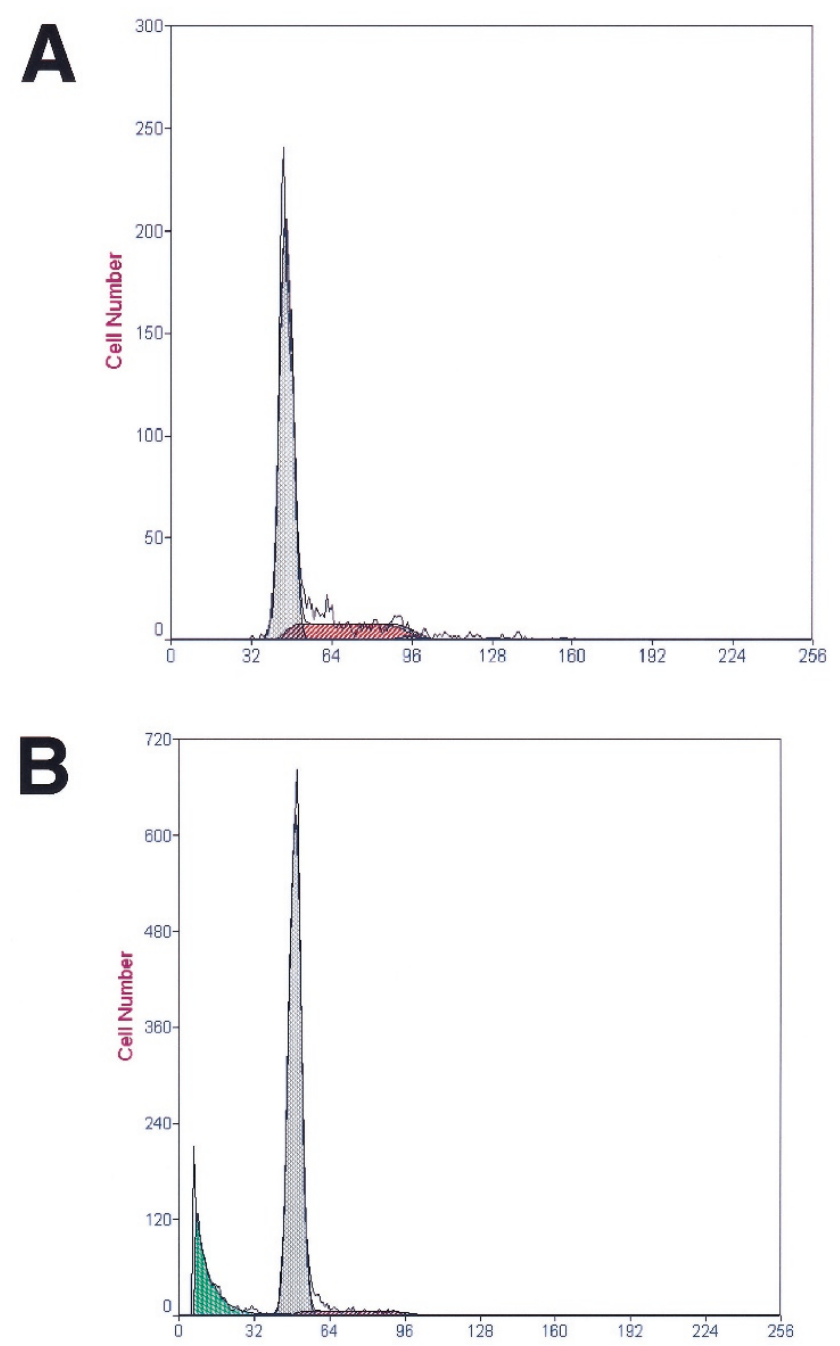

FIGURE 3. Laser capture microdissection (LCM)/flow cytometry of infiltrating duct carcinoma cells. Twenty-micron paraffin sections from the two cases shown in Figure 2 were subjected to LCM and nucleus isolation as previously described. Nuclei were stained with propidium iodide and analyzed as described in the "Methods" section. A, the analysis of the cells shown in Figure $2 \mathrm{~A}-\mathrm{C}$, with $92.8 \% \mathrm{G}_{1}, 7.2 \% \mathrm{~S}$, and no significant $\mathrm{G}_{2}$ phase populations of nuclei. In this specimen, approximately 2000 nuclei were available for analysis from one LCM cap. B, the analysis of the cells shown in Figure 2D-F, with $76.3 \% \mathrm{G}_{1}$, $22.3 \% \mathrm{~S}$, and $1.4 \% \mathrm{G}_{2}$ phase. In this specimen, approximately 5000 nuclei were available for analysis from one LCM cap. Neither specimen shows significant aneuploidy.

ficient hybridization, and nonspecific background are likely to remain. Furthermore, as the amplified signals can be large and diffuse, accurate quantification of gene copy numbers may not be possible. Although multicolor FISH is possible using tyramide technology, visualization of more than two or three fluorescent probes will be complicated by the potential for cross-reactivity between the different reagent combinations. Furthermore, nuclear slicing as a result of use of thin sections for better morphology and decreased background not unexpectedly leads to loss of genetic material, complicating quantification of amplified genes $(19,25)$.

Analysis of DNA extracted from tissue samples using Southern blotting or polymerase chain reac- tion (PCR) is still more commonly performed than interphase FISH, even though one has lost the morphologic correlates. Although whole specimen extraction is prone to contamination of cancer tissues with multiple cell types (45), the recent development of LCM technology has greatly alleviated this problem. With this equipment, precise cell typespecific microdissections can yield pure specimens for nucleic acid analysis. Although tissuedestructive techniques that can quantitate DNA preparations from LCM specimens such as quantitative PCR and Southern blotting are often used, formalin fixation and paraffin embedding both preclude Southern blot analysis and decrease the efficiency of PCR assays $(46,47)$. These techniques also destroy the individual morphology of the nuclei, compromising the specificity of the analysis and the assessment of heterogeneity.

Our results indicate that LCM specimens of breast carcinoma yield nuclei that are very amenable to multicolor FISH analysis. Twenty- to $30-\mu$ specimens yield considerable numbers of useful nuclei, samples of 10 to $15 \mu$ give a much lower yield (approximately 10 to $15 \%$ ), whereas the usual 3 - to $6-\mu$ paraffin sections evaluated morphologically do not yield nuclei appropriate for FISH or flow cytometric analysis (data not shown). Of course, these criteria are probably tumor specific, with smaller cells such as lymphocytes likely to yield useful nuclei in thinner specimens than many carcinomas or sarcomas, although we have evaluated only breast cancer specimens. We have also found that the reproducibility of the nuclear yield varies considerably between dissected samples from the same thickness of specimens (data not shown), using the same number of LCM pulses. Whether this observation is due to variations in efficiency of LCM harvesting or nucleus extraction from the LCM specimens is not clear. LCM dissection of a few thousand breast carcinoma nuclei from a 20 - to $30-\mu$ section is usually sufficient to ensure a sufficient sample for either FISH or flow cytometric analysis.

LCM/flow cytometry will allow the analysis of specific cell populations or subpopulations from even complex tumor specimens, likely decreasing artifact associated with the cell cycle analysis of specimens contaminated with both neoplastic and normal cells. LCM/FISH allows FISH to be performed on nuclei of morphologically defined cell populations harvested from paraffin-embedded specimens with ease. Furthermore, multicolor FISH may allow more sensitive assessment of copy number quantification in formalin-fixed specimens than PCR or Southern blotting, as our experience shows that most cells can give an interphase signal to a cosmid or P1-derived artificial chromosome probe. Direct labeling of DNA with fluors allows one to 
distinguish reliably many individual probes, governed only by the ability of filters to separate spectrally similar signals along the entire visible and near-infrared spectrum. Furthermore, because the nuclei are harvested from morphologically defined areas, automated analysis of the entire population of the nuclei may allow generation of gene copy fingerprints of individual cancer specimens. LCM/ FISH may have significant application to retrospective analyses of paraffin-embedded archived cancer specimens and promises to be a useful tool for use in research to identify new molecular markers of tumor progression, although the range of applications and tissue types that can benefit from this analysis has not yet been evaluated.

Acknowledgments: DJD gratefully acknowledges the Canadian Foundation for Innovation and the Terry Fox Foundation for equipment funding, Calgary Laboratory Services for clinical support, and the Medical Research Council of Canada ClinicianScientist Program for salary support. Dr. Angela Thompson is acknowledged for her initial assistance with this project.

\section{REFERENCES}

1. Andrulis IL, Bull SB, Blackstein ME, Sutherland D, Mak C, Sidlofsky S, et al. Neu/erbB-2 amplification identifies a poorprognosis group of women with node-negative breast cancer. Toronto Breast Cancer Study Group. J Clin Oncol 1998; 16(4):1340-9.

2. Eissa S, Khalifa A, el-Gharib A, Salah N, Mohamed MK. Multivariate analysis of DNA ploidy, p53, c-erbB-2 proteins, EGFR, and steroid hormone receptors for short-term prognosis in breast cancer. Anticancer Res 1997;17(4B):3091-7.

3. Tsuda H, Sakamaki C, Tsugane S, Fukutomi T, Hirohashi S. A prospective study of the significance of gene and chromosome alterations as prognostic indicators of breast cancer patients with lymph node metastases. Breast Cancer Res Treat 1998;48(1):21-32.

4. Ross JS, Sheehan C, Hayner-Buchan AM, Ambros RA, Kallakury BV, Kaufman R, et al. HER-2/neu gene amplification status in prostate cancer by fluorescence in situ hybridization. Hum Pathol 1997;28(7):827-33.

5. Berger MS, Locher GW, Saurer S, Gullick WJ, Waterfield MD, Groner B, et al. Correlation of c-erb-B2 amplification and protein expression in human breast carcinoma with nodal status and nuclear grading. Cancer Res 1988;48:1238.

6. Sauter G, Moch H, Moore D, Carroll P, Kerschmann R, Chew $\mathrm{K}$, et al. Heterogeneity of erbB-2 gene amplification in bladder cancer. Cancer Res 1993;53(10 Suppl):2199-203.

7. Saffari B, Jones LA, el-Naggar A, Felix JC, George J, Press MF. Amplification and overexpression of HER-2/neu (c-erbB2) in endometrial cancers: correlation with overall survival. Cancer Res 1995;55(23):5693-8.

8. Sauter G, Carroll P, Moch H, Kallioniemi A, Kerschmann R, Narayan P, et al. c-myc copy number gains in bladder cancer detected by fluorescence in situ hybridization. Am J Pathol 1995;146(5):1131-9.

9. Reissmann PT, Koga H, Takahashi R, Figlin RA, Holmes EC, Piantadosi S, et al. Inactivation of the retinoblastoma sus- ceptibility gene in non-small-cell lung cancer. The Lung Cancer Study Group. Oncogene 1993;8(7):1913-9.

10. Borg A, Zhang QX, Alm P, Olsson H, Sellberg G. The retinoblastoma gene in breast cancer: allele loss is not correlated with loss of gene protein expression. Cancer Res 1992;52(10): 2991-4.

11. Cunningham J, Lust JA, Schaid DJ, Bren GD, Carpenter HA, Rizza E, et al. Expression of p53 and 17p allelic loss in colorectal carcinoma. Cancer Res 1992;52(7):1974-80.

12. Thompson AM, Anderson TJ, Condie A, Prosser J, Chetty U, Carter DC, et al. p53 allele losses, mutations and expression in breast cancer and their relationship to clinicopathological parameters. Int J Cancer 1992;50(4):528-32.

13. Eccles DM, Brett L, Lessells A, Gruber L, Lane D, Steel CM, et al. Overexpression of the p53 protein and allele loss at 17p13 in ovarian carcinoma. Br J Cancer 1992;65(1):40-4.

14. Kallioniemi O-P, Kallioniemi A, Kurisu W, Thor A, Chen L-C, Smith HS, et al. ERBB2 amplification in breast cancer analyzed by fluorescent in situ hybridization. Proc Natl Acad Sci U S A 1992;89:5321.

15. Deng G, Yu M, Chen LC, Moore D, Kurisu W, Kallioniemi A, et al. Amplifications of oncogene erbB-2 and chromosome $20 \mathrm{q}$ in breast cancer determined by differentially competitive polymerase chain reaction. Breast Cancer Res Treat 1996;40(3):271-81.

16. Xing WR, Gilchrist KW, Harris CP, Samson W, Meisner LF. FISH detection of HER-2/neu oncogene amplification in early onset breast cancer. Breast Cancer Res Treat 1996; 39(2):203-12.

17. Persons DL, Borelli KA, Hsu PH. Quantitation of HER-2/neu and c-myc gene amplification in breast carcinoma using fluorescence in situ hybridization. Mod Pathol 1997;10(7): 720-7.

18. Press MF, Bernstein L, Thomas PA, Meisner LF, Zhou JY, Ma Y, et al. HER-2/neu gene amplification characterized by fluorescence in situ hybridization: poor prognosis in nodenegative breast carcinomas. J Clin Oncol 1997;15(8):2894904.

19. Visscher DW, Wallis T, Ritchie CA. Detection of chromosome aneuploidy in breast lesions with fluorescence in situ hybridization: comparison of whole nuclei to thin tissue sections and correlation with flow cytometric DNA analysis. Cytometry 1995;21(1):95-100.

20. Kallioniemi A, Kallioniemi OP, Waldman FM, Chen LC, Yu LC, Fung YK, et al. Detection of retinoblastoma gene copy number in metaphase chromosomes and interphase nuclei by fluorescence in situ hybridization. Cytogenet Cell Genet 1992;60(3-4):190-3.

21. Papa V, Milazzo G, Goldfine ID, Waldman FM, Vigneri R. Sporadic amplification of the insulin receptor gene in human breast cancer. J Endocrinol Invest 1997;20(9):531-6.

22. Demetrick D. The use of archival frozen tumour tissue specimens for fluorescence in situ hybridization. Mod Pathol 1996;9:133-6.

23. Theodorescu D, Cornil I, Sheehan C, Man S, Kerbel RS. Dominance of metastatically competent cells in primary murine breast neoplasms is necessary for distant metastatic spread. Int J Cancer 1991;47:118-23.

24. Simpson JF, Quan DE, Ho JP, Slovak ML. Genetic heterogeneity of primary and metastatic breast carcinoma defined by fluorescence in situ hybridization. Am J Pathol 1996;149(3): 751-8.

25. Qian J, Bostwick DG, Takahashi S, Borell TJ, Brown JA, Lieber $\mathrm{MM}$, et al. Comparison of fluorescence in situ hybridization analysis of isolated nuclei and routine histological sections from paraffin-embedded prostatic adenocarcinoma specimens. Am J Pathol 1996;149(4):1193-9. 
26. McKay JA, Murray GI, Keith WN, McLeod HL. Amplification of fluorescent in situ hybridisation signals in formalin fixed paraffin wax embedded sections of colon tumour using biotinylated tyramide. Mol Pathol 1997;50(6):322-5.

27. Heiden T, Wang N, Bernhard T. An improved Hedley method for preparation of paraffin-embedded tissues for flow-cytometric analysis of ploidy and S phase. Cytometry 1991;12:614-21.

28. Hedley DW, Friedlander ML, Taylor IW, Rugg CA, Musgrove CA. Method for analysis of cellular DNA content of paraffinembedded pathological material using flow cytometry. J Histochem Cytochem 1983;31:1333-5.

29. Hyytinen E, Visakorpi T, Kallioniemi A, Kallioniemi OP, Isola JJ. Improved technique for analysis of formalin-fixed, paraffin-embedded tumors by fluorescence in situ hybridization. Cytometry 1994;16(2):93-9.

30. Baldetorp B, Stal O, Ahrens O, Cornelisse C, Corver W, Falkmer U, et al. Different calculation methods for flow cytometric S-phase fraction: prognostic implications in breast cancer? The Swedish Society of Cancer Study Group. Cytometry 1998;33(4):385-93.

31. Wong SW, Rangan AM, Bilous AM, Boyages J, Gebski V, Benson EM. The value of S-phase and DNA ploidy analysis as prognostic markers for node-negative breast cancer in the Australian setting. Pathology 1999;31(2):90-4.

32. McCormick SR, Peters AA, Schrauth JB. Flow cytometric DNA analysis with cytokeratin gating of formalin-fixed deparaffinized breast cancer nuclei. Am J Clin Pathol 1998; 110(2):227-37.

33. Emmert-Buck MR, Bonner RF, Smith PD, Chuqui RF, Zhuang Z, Goldstein SR, et al. Laser capture microdissection. Science 1996;274:998-1001.

34. Sgroi DC, Teng S, Robinson G, LeVangie R, Hudson JR Jr, Elkahloun AG. In vivo gene expression profile analysis of human breast cancer progression. Cancer Res 1999;59(22): 5656-61.

35. Rajcan-Separovic E, Wang HS, Speevak MD, Janes L, Korneluk RG, Wakasa K, et al. Identification of the origin of double minutes in normal human cells by laser-based chromosome microdissection approach. Hum Genet 1995;96(1): $39-43$.

36. Aubele M, Mattis A, Zitzelsberger H, Walch A, Kremer M, Hutzler $\mathrm{P}$, et al. Intratumoral heterogeneity in breast carcinoma revealed by laser-microdissection and compara- tive genomic hybridization. Cancer Genet Cytogenet 1999; 110(2):94-102.

37. Banks RE, Dunn MJ, Forbes MA, Stanley A, Pappin D, Naven $\mathrm{T}$, et al. The potential use of laser capture microdissection to selectively obtain distinct populations of cells for proteomic analysis-preliminary findings. Electrophoresis 1999;20(45):689-700.

38. Liehr T, Grehl H, Rautenstrauss B. FISH analysis of interphase nuclei extracted from paraffin-embedded tissue. Trends Genet 1995;11(10):377-8.

39. Taylor IW, Milthorpe BK. An evaluation of DNA fluorochromes, staining techniques, and analysis for flow cytometry: I. Unperturbed cell populations. J Histochem Cytochem 1980;28(11):1224-32.

40. Frierson HFJ, Wolber RA, Berean KW, Franquemont DW, Gaffey MJ, Boyd JC, et al. Interobserver reproducibility of the Nottingham modification of the Bloom and Richardson histologic grading scheme for infiltrating ductal carcinoma. Am J Clin Pathol 1995;103:195-8.

41. Mosiman VL, Patterson BK, Canterero L, Goolsby CL. Reducing cellular autofluorescence in flow cytometry: an in situ method. Cytometry 1997;30(3):151-6.

42. Szollosi J, Lockett SJ, Balazs M, Waldman FM. Autofluorescence correction for fluorescence in situ hybridization. Cytometry 1995;20(4):356-61.

43. Thompson CT, LeBoit PE, Nederlof PM, Gray JW. Thicksection fluorescence in situ hybridization on formalin-fixed, paraffin-embedded archival tissue provides a histogenetic profile. Am J Pathol 1994;144(2):237-43.

44. de Haas RR, Verwoerd NP, van der Corput MP, van Gijlswijk RP, Siitari H, Tanke HJ. The use of peroxidase-mediated deposition of biotin-tyramide in combination with timeresolved fluorescence imaging of europium chelate label in immunohistochemistry and in situ hybridization. J Histochem Cytochem 1996;44(10):1091-9.

45. Giercksky HE, Thorstensen L, Qvist H, Nesland JM, Lothe RA. Comparison of genetic changes in frozen biopsies and microdissected archival material from the same colorectal liver metastases. Diagn Mol Pathol 1997;6(6):318-25.

46. Pavelic J, Gall-Troselj K, Bosnar MH, Kardum MM, Pavelic K. PCR amplification of DNA from archival specimens. A methodological approach. Neoplasma 1996;43(2):75-81.

47. Wiegand P, Domhover J, Brinkmann B. [DNA degradation in formalin fixed tissues.] [German] Pathologe 1996;17(6):451-4. 